\title{
Laparoscopic monolateral suspension for vaginal vault prolapse: a report of an exit surgical strategy during sacralcolpopexy
}

Federico Romano ${ }^{1 *} \mathbb{D}$, Andrea Sartore ${ }^{1}$, Denise Mordeglia², Giovanni Di Lorenzo ${ }^{1}$, Guglielmo Stabile ${ }^{1}$ and Giuseppe Ricci ${ }^{1,2}$

\begin{abstract}
Background: Vaginal vault prolapse is the most frequent long-term complication in patients undergoing hysterectomy and sacralcolpopexy is considered the gold standard. We report our surgical strategy maintaining single-arm mesh when the sacral promontory is not accessible to fix the mesh for an unknown sacral osteophytosis during a laparoscopic sacralcolpopexy. This is significant because, to our knowledge, the bone variant as a procedure limiting factor has never been described before. This opens new horizons for the sacralcolpopexy surgery, because it becomes necessary to know of a valid surgical alternative with mesh maintenance if this complication occurs again or to perform an assessment of the accessibility of the sacral promontory immediately after its dissection.

Case presentation: We present a case of a 75-year-old woman with recurrence of vaginal vault prolapse. A laparoscopic sacralcolpopexy was recommended. During surgery, we found that the procedure was not feasible due to the presence of an unknown osteophytosis of the sacrum which prevented the fixing of the mesh to the sacral promontory. We decided to proceed with a single-arm lateral suspension by using a modified approach of the original technique, maintaining the mesh originally shaped for the sacral colpopexy. At follow-up, the vaginal vault is well suspended.
\end{abstract}

Conclusion: This exit strategy may represent a valid surgical alternative when laparoscopic sacral colpopexy is not possible for anatomical variants, allowing to keep the laparoscopic approach using mesh. To our knowledge, cases in which the anatomical bone variant prevented access to the sacral promontory have never been described in the literature, as bone evaluation has never been considered a limiting element of this procedure.

Keywords: Laparoscopic lateral colposuspension, Osteophytosis, Promontory dissection, Sacralcolpopexy, Vaginal vault prolapse

\footnotetext{
* Correspondence: federico.romano@burlo.trieste.it

'Institute for Maternal and Child Health, I.R.C.C.S. "Burlo Garofolo", Trieste, Italy

Full list of author information is available at the end of the article
}

(c) The Author(s). 2020 Open Access This article is licensed under a Creative Commons Attribution 4.0 International License, which permits use, sharing, adaptation, distribution and reproduction in any medium or format, as long as you give appropriate credit to the original author(s) and the source, provide a link to the Creative Commons licence, and indicate if changes were made. The images or other third party material in this article are included in the article's Creative Commons licence, unless indicated otherwise in a credit line to the material. If material is not included in the article's Creative Commons licence and your intended use is not permitted by statutory regulation or exceeds the permitted use, you will need to obtain permission directly from the copyright holder. To view a copy of this licence, visit http://creativecommons.org/licenses/by/4.0/ The Creative Commons Public Domain Dedication waiver (http://creativecommons.org/publicdomain/zero/1.0/) applies to the data made available in this article, unless otherwise stated in a credit line to the data. 


\section{Background}

Vaginal vault prolapse is the major long-term complication in patients undergoing hysterectomy and occurs, approximately, in $0.2-43 \%$ of the cases. The cause is the detachment of the pubocervical and rectovaginal fascia from each other, from their apical support, the uterosacral and cardinal ligaments or DeLancey's level first support. The clinical management of this pathology remains a critical field, as demonstrated by the broad spectrum of surgical techniques developed so far [1].

The literature considers the sacralcolpopexy as the gold standard for vaginal vault prolapse, with a longterm success rates of $>90 \%$ and the most appropriate reconstruction of the physiological axis of the vagina [2]. Abdominal sacralcolpopexy has long been considered a safe and successful surgical procedure for the prolapse of the vaginal vault and has become the gold standard of care. The surgical approach may be abdominal by laparotomy, laparoscopy or robot-assisted [3]. Laparoscopic surgery combines the advantages of a repair, which is identical to the open transabdominal technique, with the advantages of vaginal surgery. Theoretically, all pelvic repair methods requiring laparotomy can also be performed with laparoscopy, which offers an excellent overall approach in the treatment of vaginal vault prolapse. It allows better visualization of the anterior and posterior pelvic anatomy obtained by pneumoperitoneal pressure which leads to a satisfactory repair [1]. Laparoscopic procedures have the disadvantage of having a longer operating time, which improves with the surgeon's experience [4].

We report our experience which can represent a valid surgical alternative when the sacral promontory is inaccessible and the mesh is already fixed during laparoscopic sacralcolpopexy.

\section{Case presentation}

We present the case of a 75-year-old woman who underwent a laparoscopic monolateral suspension for vaginal vault prolapse. The patient was a Caucasian woman in good general health with two previous spontaneous deliveries and a vaginal hysterectomy for uterine prolapse in 2001.

She was admitted to our hospital with a diagnosis of a recurrence of stage 4 of vaginal vault prolapse following the Pelvic Organ Prolapse Quantification (POP-Q) System, without stress urinary incontinence. The main symptoms she reported were a sense of weight and vaginal pressure. Considering the anamnesis, pelvic examination, clinical symptoms, and recurrence of pelvic organ prolapse, the surgical procedure chosen was a laparoscopic sacral colpopexy. The patient received adequate information on the surgical technique via laparoscopic access and, in case needed, via laparotomic or vaginal access.

A consent form was provided and signed. During surgery, the parietal peritoneum was opened at the level of the sacral promontory with subsequent incision of the presacral fascia and identification of the longitudinal ligament. After the visualization of the right ureter and homolateral hypogastric inferior right nerve [3], we performed a recto-vaginal dissection toward the perineal and anorectal junction together with dissection of the vesicovaginal space until the endopelvic fascia.

In our surgical practice, a $30 \times 30 \mathrm{~cm}$ polypropylene mesh (Restorelle XL- Coloplast A/S, 3050 Denmark) with a single arm is used. Before its insertion in the abdominal cavity, the mesh is tailored only in the portion that will be anchored to the vaginal and rectal space, while the other end is left intact in its length and subsequently tailored after its attachment to the sacral promontory.

After the mesh was anchored on the vesical-vaginal space with 12 interrupted sutures (Ethibond 3-0 needle), multiple attempts to fix the mesh to the sacral promontory were tried firstly with an Ethibond 0 needle and then with non-absorbable helicoidal clips (5 $\mathrm{mm}$ CapSure-Permanent fixation System. Davol Inc. Subsidiary of C.R. Bard, Inc. 100 Crossings Boulevard Warwick, RI 02886 USA) but any attempt to penetrate the site was unsuccessful (Fig. 1). Considering that the mesh was already fixed to the anterior and posterior vaginal compartment, we intraoperatively decided to convert the procedure into a modified laparoscopic lateral suspension (LLS) with a monolateral right mesh, on the basis of the original technique described by Dubuisson et al., where a V-shaped mesh is used [5]. We carried out a retroperitoneal tunnel using laparoscopic forceps through the right lateral access under transperitoneal visualization, putting in tension and fixing the mesh to the Camper fascia with two interrupted sutures, using an Ethibond 2-0 needle.

At the end of the procedure, the vaginal vault was well suspended (Fig. 2). This strategy was possible because the sacral portion of the mesh was not shaped before its fixation to the sacral promontory and was long enough to allow its anchorage to the right lateral Camper fascia.

During the post-operative recovery, we performed a $3 \mathrm{D}$ reconstruction $\mathrm{CT}$ scan to evaluate the sacrum which detected an exuberant osteophytic bridge at the level of the anterior right margin of L5 and S1 that protruded for $17 \mathrm{~mm}$ (Figs. 3 and 4).

The patient was discharged after 3 postoperative days with no post-surgical complication. At the follow-up visit, scheduled at 6 months after surgery, the vaginal vault was well suspended, with no signs of genital prolapse. The patient reported clinical well-being, without pelvic pressure or sensation of a vaginal bulge.

\section{Discussion and conclusions}

Due to the surgical complexity and the high risk of injuring primary structures, the dissection of the promontory is 


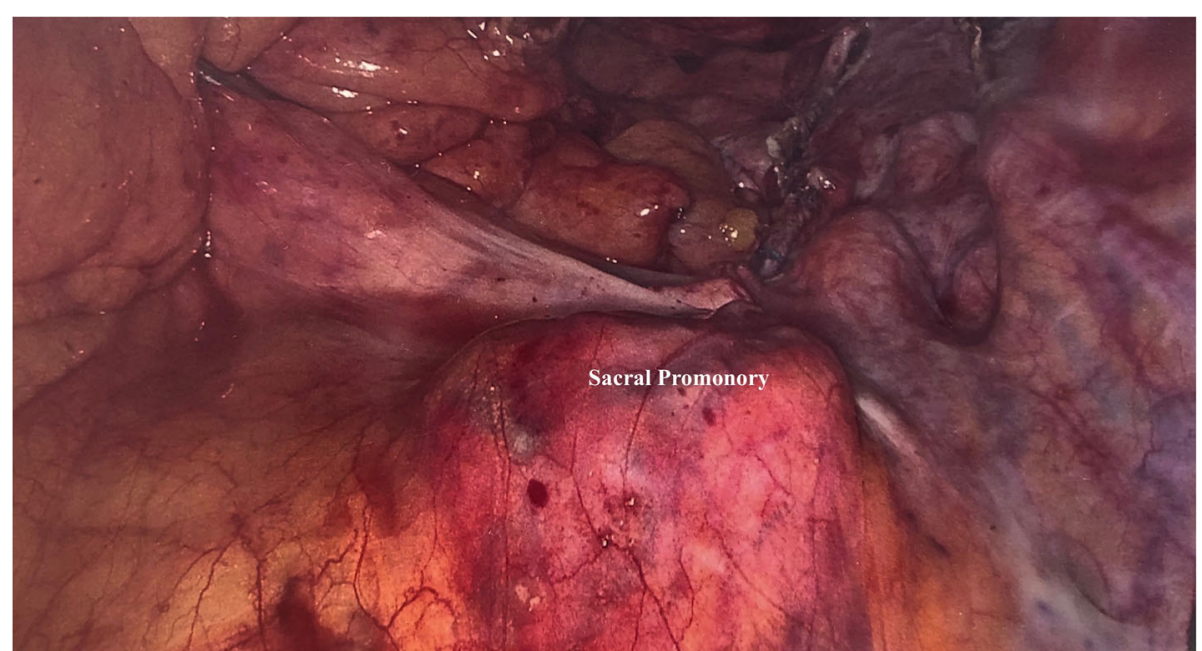

Fig. 1 Laparoscopic image: sacral promontory

considered the first surgical step [6]. The presacral area is defined as a retroperitoneal pyramid-shaped area that extends below the aortic bifurcation to the pelvic floor, bordered laterally by the internal iliac vessels. The peritoneal dissection generally begins from the sacral promontory, which represents an important bony landmark, and then extend downwards to expose the anterior longitudinal ligament [7]. The right ureter should be seen throughout the entire dissection process in order to avoid damages to the right iliac vessels and ureter. The vascular anatomy is extremely variable [8]. To date, the literature has strongly emphasized these variants which must be known to avoid bleeding complications, while the bone component and the study of the bone promontory were less explored.

An alternative procedure to the sacral colpopexy is the laparoscopic lateral suspension with a V-shaped mesh: this technique showed good results in terms of feasibility, postoperative results and patient's satisfaction while avoiding the risks and difficulties related to the dissection of the promontory, requiring a shorter learning

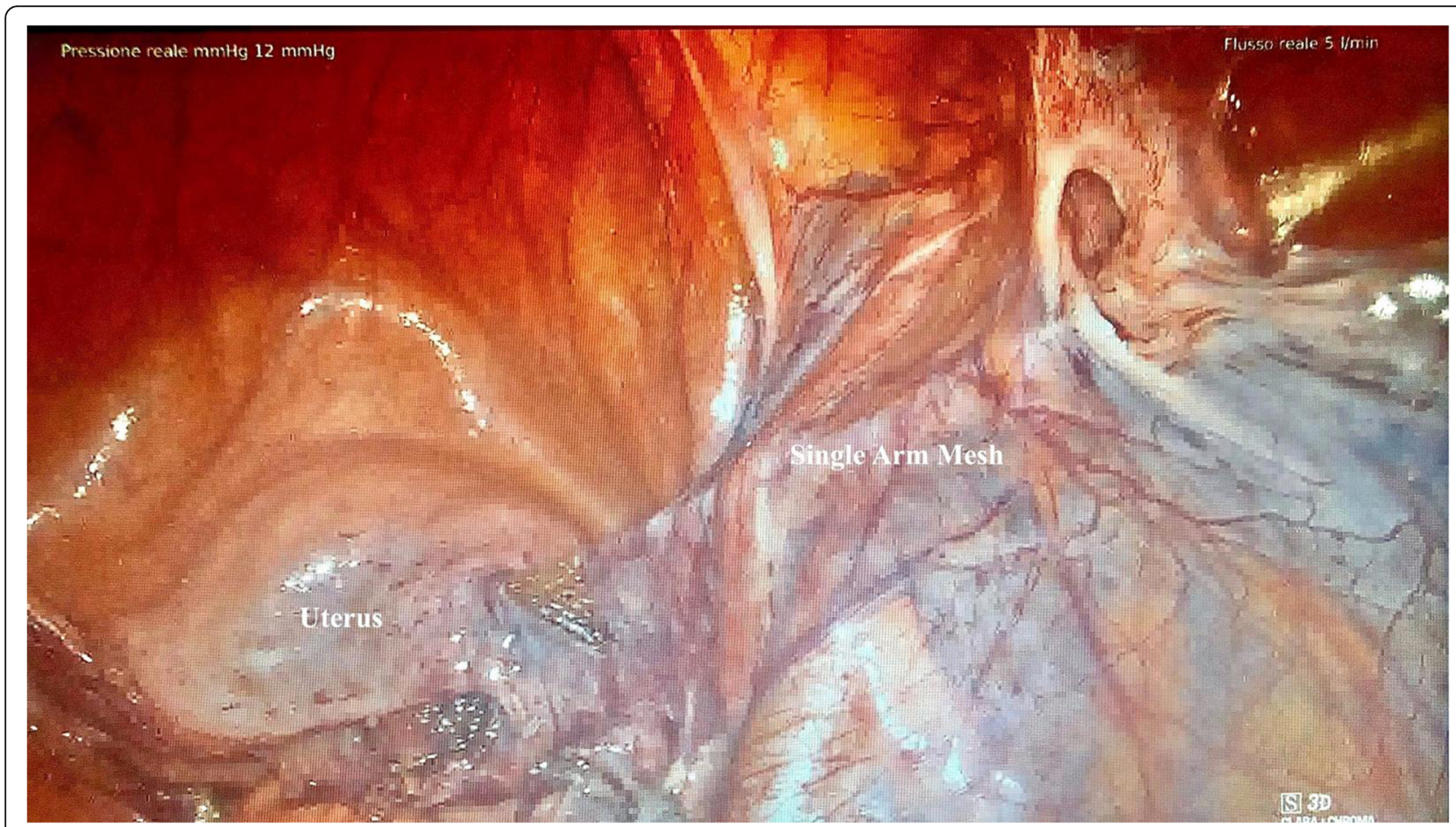

Fig. 2 Laparoscopic image: lateral colposuspension of the mesh 


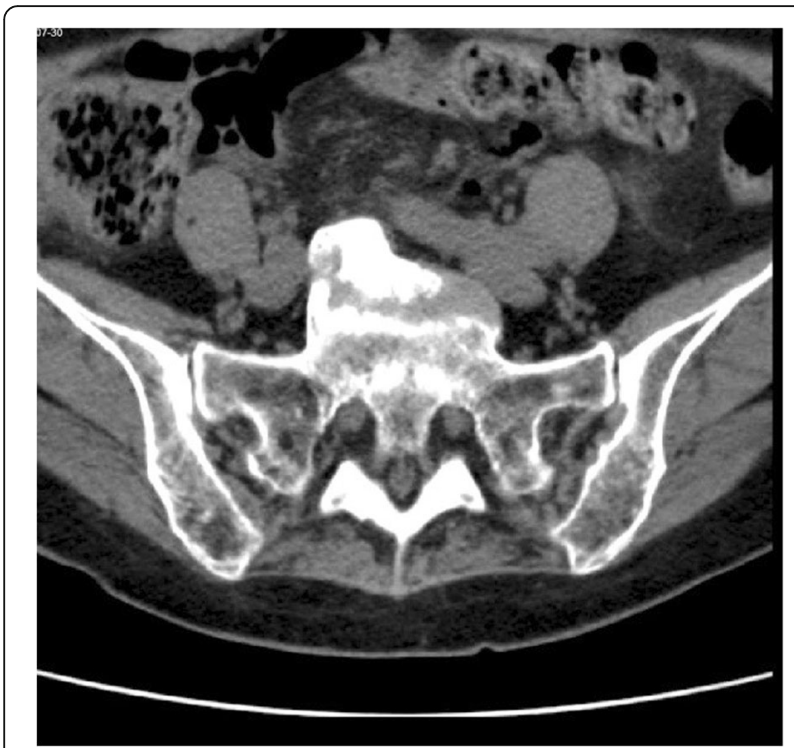

Fig. 3 Transverse plane CT scan: sacral promontory

curve [9]. The choice of any of these procedures depends on patients' clinical characteristics and surgical skills.

In our case, we were not aware of any previous traumatic event or clinical history that could raise the suspicion for anatomical variants of the sacral promontory and only postoperatively the patient referred a ski fall at a young age, that cannot be surely linked to the osteophyte. Moreover, the presence of the osteophytic bridge did not affect the normal dissection of the anatomical spaces and its presence was revealed only when we attempted to attach the mesh to the sacral promontory.

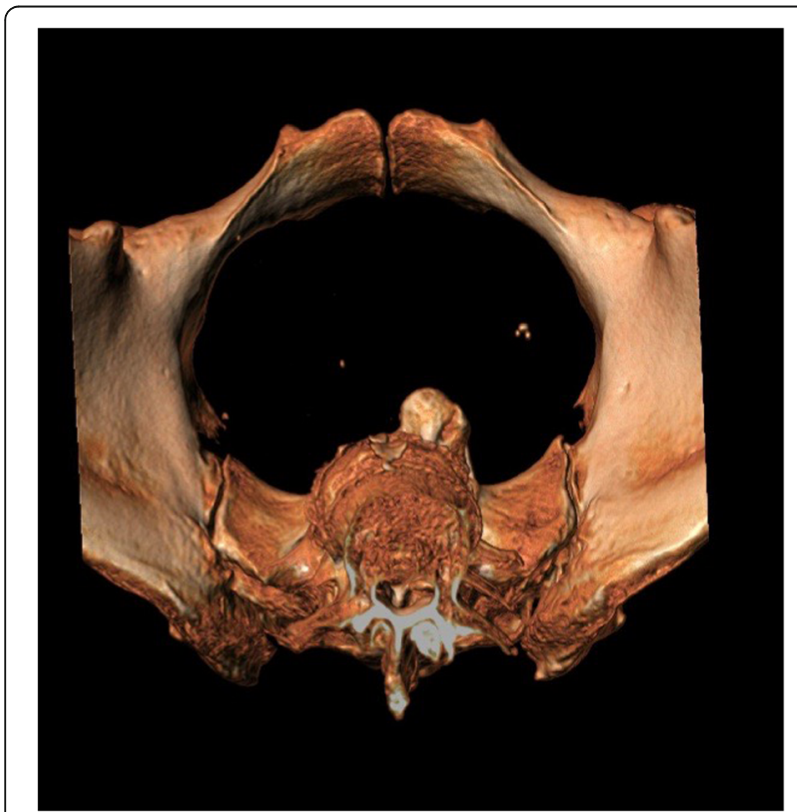

Fig. 4 Transverse plane 3D CT scan: sacral promontory
To our knowledge, this is the first case where an anatomical bone variant prevented to complete successfully the sacral colpopexy. Considering the rarity of this complication, it is not reasonable to recommend a radiological evaluation to all the patients who will undergo a laparoscopic sacral colpopexy. Therefore, our experience highlights two aspects: the first is the importance of carrying on a detailed clinical history in the preoperative time; the second, is to perform a tactile evaluation using laparoscopic instruments, which allow to obtain important information in the hands of experienced surgeons.

In case the anatomical variant is not detected before surgery, it is essential to think of an alternative strategy that allows to complete the procedure by keeping the laparoscopic approach and maintaining the mesh. Our modified laparoscopic monolateral suspension with a single-arm mesh, never described before, allowed us to overcome the surgical complication of an inaccessible promontory constituting a valid rescue surgical alternative.

Of note, a critical component of our surgical technique that allowed us to rapidly convert the approach was the possibility of using the mesh along its entire length. For this reason, a good surgical practice when approaching sacral colpopexy could be to shape the mesh longitudinally in width but not in length, modelling the proximal portion and cutting the distal end only after the completion of the fixation procedure.

We had a mid-term follow-up of 6 months that showed a good anatomical correction of the vaginal vault prolapse without relapse of the disease, despite the monolateral tension only on the right side. This aspect supports the feasibility of the described technique that could be of help for other surgeons facing similar anatomical variants.

The strengths of this case report are the feasible and safe reproducibility of this surgical procedure in case the sacralcolpopexy could not be completed with the possibility of maintaining the mesh and the laparoscopic surgical approach. The main limitation is that this procedure was performed on only one patient with short-term follow-up.

Our novel surgical technique consists in a laparoscopic monolateral suspension with a single arm mesh anchored only to one side of the Camper' fascia. This approach, intraoperatively designed to overcome the unexpected finding of an anatomical bone variant, allowed us to complete successfully the surgery by keeping the laparoscopic approach and using the same mesh shaped for the originally procedure. Moreover, we highlight the importance of considering bone variants in the preoperative assessment of patients undergoing sacralcolpopexy, identifying different surgical strategies.

\section{Acknowledgements}

The authors acknowledge Martina Bradaschia MD for the English revision of the manuscript. 


\section{Authors' contributions}

FR and AS analyzed and interpreted the patient data regarding the gynecological disease. FR, AS and DM performed the surgery. GDL, GS and RG had contributed to the analysis and the interpretation of data. All authors had contributed to the conception design of the work. Each author read and approved the final manuscript.

\section{Funding}

This research was funded by the Italian Ministry of Healt (RC 08/2020 Institute for Maternal and Child Healt IRCCS Burlo Garofolo).

\section{Availability of data and materials}

Data sharing is not applicable to this article as no datasets were generated or analyzed during the current study.

\section{Ethics approval and consent to participate}

ID Study 3121 Internal Code: RC 18/2019.

Our local Institutional Review Board was consulted regarding this case report. The work has been submitted and approved by our Internal

Review Board.

\section{Consent for publication}

Written informed consent for publication of clinical details and/or clinical images was obtained from the patient. A copy of the consent form is available for review by the Editor of this journal.

\section{Competing interests}

The authors declare that they have no competing interests.

\section{Author details}

"Institute for Maternal and Child Health, I.R.C.C.S. "Burlo Garofolo", Trieste, Italy. ${ }^{2}$ Department of Medical, Surgical, and Health Sciences, University of Trieste, Trieste, Italy.

Received: 1 July 2020 Accepted: 6 September 2020 Published online: 11 September 2020

\section{References}

1. Granese R, Candiani M, Perino A, Romano F, Cucinella G. Laparoscopic sacrocolpopexy in the treatment of vaginal vault prolapse: 8 years experience. Eur J Obstet Gynecol Reprod Biol. 2009;146(2):227-31.

2. Szymczak P, Grzybowska ME, Wydra DG. Comparison of laparoscopic techniques for apical organ prolapse repair - a systematic review of 182 the literature. Neurol Urodyn. 2019:38(8):2031-50.

3. Romano F, Legge F, Scambia G, Guido M. Nerve-sparing laparoscopic colposacropexy using a percutaneous surgical system: a case report. J Minim Invasive Gynecol. 2017;24(4):536-7.

4. Deprest J, Krofta L, Van der Aa F, Milani AL, Den Boon J, Claerhout F, Roovers JP. The challenge of implementing laparoscopic sacrocolpopexy. Int Urogynecological. 2014;25(9):1153-60.

5. Dubuisson JB, Veit-Rubin N, Bouquet de Jolinièere J, Dubuisson JB. Laparoscopic Lateral Suspension: Benefits of a Cross-shaped Mesh to Treat Difficult Vaginal Vault Prolapse. J Minim Invasive Gynecol. 2016;23(5):672.

6. Gadonneix P, Kane A, Vincens E, Salet Lizee D, Villet R. Laparoscopic promonto- fixation for urogenital prolapsus. J Visc Surg. 2015;152(1):45-55. https://doi.org/10.1016/j.jviscsurg.2014.11.002.

7. Good M, Abele T, Balgobin S, Montoya TI, McIntire D, Corton MM. Vascular and ureteral anatomy relative to the midsacral promontory. Am J Obstet Gynecol. 2013;208(6):486.e1-486.e4867.

8. Chong GO, Lee YH, Hong DG, Cho YL, Lee YS. Anatomical variations of the internal iliac veins in the Presacral area: clinical implications during sacral Colpopepxy or extended pelvic lymphadenectomy. Clin Anat. 2015;28(5):661-4.

9. Veit-Rubin N, Dubuisson JB, Angèle G-A, Lange S, Eperon I, Dubuisson J. Patient Satisfaction After Laparoscopic Lateral Suspension With Mesh For Pelvic Organ Prolapse: Outcome Report Of A Continuous Series Of 417 Patients. Int Urogynecol J. 2016;28(11):1685-93.

\section{Publisher's Note}

Springer Nature remains neutral with regard to jurisdictional claims in published maps and institutional affiliations.

Ready to submit your research? Choose BMC and benefit from:

- fast, convenient online submission

- thorough peer review by experienced researchers in your field

- rapid publication on acceptance

- support for research data, including large and complex data types

- gold Open Access which fosters wider collaboration and increased citations

- maximum visibility for your research: over $100 \mathrm{M}$ website views per year

At $\mathrm{BMC}$, research is always in progress.

Learn more biomedcentral.com/submissions 